\title{
Diabetes in Pakistan: A systematic review and meta-analysis
}

\author{
Sohail Akhtar', Jamal Abdul Nasir ${ }^{2}$, \\ Tahir Abbas ${ }^{3}$, Aqsa Sarwar ${ }^{4}$
}

\begin{abstract}
Objective: The purpose of this study was assess the time trend of the prevalence of prediabetes and diabetes and risk factors associated with diabetes in Pakistan by using a systematic review and metaanalysis.

Methods: A systematic literature search of Embase, PubMed, and the Cochrane library was carried out between January 1, 1995 and August 30, 2018. Diabetes and prediabetes prevalence estimates were combined by the random-effects model. The existence of publication bias was tested by Egger regression. This systematic review was reported following the PRISMA guidelines.

Results: The search conceded a total of 635 studies, only 14 studies were considered for meta-analysis. The prevalence of diabetes in Pakistan was revealed 14.62\% (10.651\%-19.094\%; 14 studies) based on 49,418 people using the inverse-variance random-effects model. The prevalence of prediabetes was $11.43 \%$ (8.26\%-15.03\%; 10 studies) based on a total sample of 26,999 people. The risk factors associated with diabetes were mean age $(B=0.48 \%, 95 \% \mathrm{Cl}: 0.21-0.78, \mathrm{p}<0.001)$, the proportion of participants with a family history of diabetes $(B=0.45 \%, 95 \% \mathrm{Cl}: 0.08-0.82, p=0.018, p<0.001)$, hypertension $(B=0.40 \%, 95 \%$ $\mathrm{Cl}: 0.06-0.75, \mathrm{p}=0.022)$, weight (BMI) $(B=0.21 \%, 95 \% \mathrm{Cl}: 0.02-0.4, \mathrm{p}=0.030)$.

Conclusions: There has been a continuous increase in the prevalence of prediabetes and diabetes in Pakistan. All parts of the country have been affected, with the highest in Sindh and lowest in Khyber Pakhtunkhwa. The main factors include growing age, family history, hypertension and obesity. A nationwide diabetes care survey on risk factors and prevention policy is highly recommended.
\end{abstract}

KEYWORDS: Diabetes, Prediabetes, Pakistan, Meta-analysis and Systematic review.

doi: https://doi.org/10.12669/pjms.35.4.194

How to cite this:

Akhtar S, Nasir JA, Abbas T, Sarwar A. Diabetes in Pakistan: A systematic review and meta-analysis. Pak J Med Sci. 2019;35(4):1173-1178. doi: https://doi.org/10.12669/pjms.35.4.194

This is an Open Access article distributed under the terms of the Creative Commons Attribution License (http://creativecommons.org/licenses/by/3.0), which permits unrestricted use, distribution, and reproduction in any medium, provided the original work is properly cited.

1. Dr. Sohail Akhtar, PhD.

2. Dr. Jamal Abdul Nasir, PhD.

3. Dr. Tahir Abbas, PhD.

4. Aqsa Sarwar, BS Student.

1-4: Department of Statistics,

Government College University Lahore,

Lahore, Pakistan.

Correspondence:

Dr. Sohail Akhtar, PhD.

Associate Professor, (Chairperson),

Department of Statistics,

Government College University Lahore,

Katchery Road,

Lahore, Pakistan.

Email: S.akhtar@gcu.edu.pk, Akhtar013@gmail.com

* Received for Publication:

* Revision Received:

* Revision Accepted:

April 20, 2019
December 14, 2018

April 30, 2019

\section{INTRODUCTION}

Diabetes is one of the fastest rising public health issues and causing a number of serious health complications. The prevalence of diabetes is growing globally due to aging factor, physical inactivity, overweight, urbanization, sedentary lifestyle and poor eating habits. ${ }^{1}$ Globally, it has been projected that the number of diabetes people will be rising to 693 million by 2045 from 451 million in 2017. ${ }^{2}$ It is also estimated that $49.7 \%$ of people living with type-II diabetes are undiagnosed. ${ }^{3}$ In the patients with type-II diabetes, the average life expectancy is decreased by around 10 years. ${ }^{4}$ In the developing countries, majority of diabetes patients are under 64 years of age, while in developing countries, 
most are in higher age groups. ${ }^{2}$ Diabetes in adult population is expected by 69 percent from 2010 to 2030 in the developing countries as compared to 20 percent for developed countries. ${ }^{4,5}$ Pakistan is a developing country and facing a sharp growth in the prevalence of diabetes. Although, several research studies have been performed to investigate the prevalence of diabetes and its associated risk factors, but estimates of the prevalence of diabetes vary widely from study to study. There are no solid and consistent prevalence data are available to find the trends over time period. The purpose of this study was to summarize current data to find out the trends and pooled prevalence of diabetes, prediabetes and undiagnosed diabetes in a general adult population living in Pakistan. Furthermore, we also analyzed the correlated risk factors of diabetes.

\section{METHODS}

Search Strategy: We systematically searched articles on PubMed, Medline, EMBASE, the Cochrane Library, and Pakistani Journals Online websites [for example: Journal of Pakistan Medical Association (www.jpma.org.pk/); Journals of the College of Physicians and Surgeons Pakistan (www.jcpsp.pk); Pakistan Journal of Medical Sciences (www.pjms.org.pk), etc] from January 1995 to August 2018. Using MeSH headings, the terms "diabetes mellitus," "prediabetes", "Impaired glucose tolerance (IGT)", "risk factors", "prevalence," "glucose abnormalities", "glucose intolerance" \& "Pakistan" as well as variations thereof were searched for. Results were described using the Preferred Reporting Items for Systematic and Meta-analyses (PRISMA) guidelines (Table-I) ${ }^{6}$

Inclusion and exclusion criteria: Only population based studies that were carried out between January 1995 and August 2018 were considered in the meta-analysis. Hospital-based and clinical studies were excluded from the meta-analysis. Pakistani community living outside Pakistan, or those studies considered pregnant women or children were excluded from the analysis.

Data Extraction: Different information was extracted from the qualified studies, such as first author name, year of publication, gender, age, studied sample, the prevalence rate of diabetes and prediabetes, smoking, survey year, study setting (urban, rural or both) study design, sampling method, and geographic region (province) in which the study was carried out. An extract of the data is presented Table-I.

Statistical Analyses: The prevalence of diabetes and prediabetes were examined and analyzed us- ing the software R version. 3.5.1. ${ }^{7}$ for Microsoft Windows, using two packages meta 4.9-2 and metafor 2.0. Random effect meta-analysis models were used to find out the pooled prevalence for diabetes, prediabetes and undiagnosed diabetes. Because of the considerable heterogeneity observed between individual studies, a random-effects meta-analysis was used to adjust for variability and pool the study specific prevalence rates. ${ }^{8,9}$ To stabilize the variance of each study, we used Freeman Tukey Double Arcsine transformation..$^{10}$ For quantifying statistical Heterogeneity across studies, Cochrane's Q-statistic, ${ }^{11}$ and $\mathrm{I}^{2}$-Statistic were used. ${ }^{12}$ Heterogeneity was categorized as high, moderate, low and, with $I^{2}$ value $75 \%$, $50 \%$ and $25 \%$ respectively. To investigate possible reasons of heterogeneity, meta-regression and subgroup analyses were used by areas, year of publication, gender, and age. The existence of publication bias was initially checked by the graphical display of funnel plot and then test by the Egger's. ${ }^{13,14}$

Literature Search: The literature search yielded 635 articles eligible for analysis. Five hundred and fourteen duplicated studies were removed. After

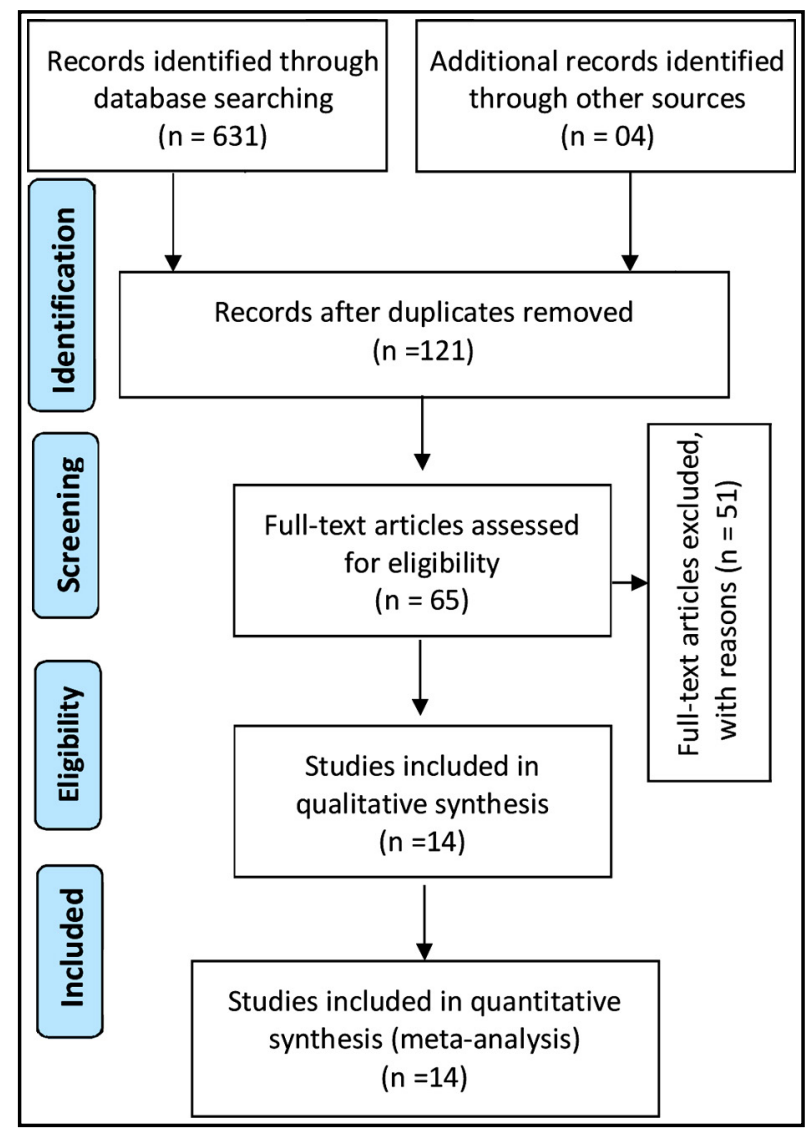

Fig.1: Flow diagram explaining the number of included and excluded articles in the meta-analysis on diabetes in Pakistan, considered from the PRISMA 2009 guideline. ${ }^{6}$ 


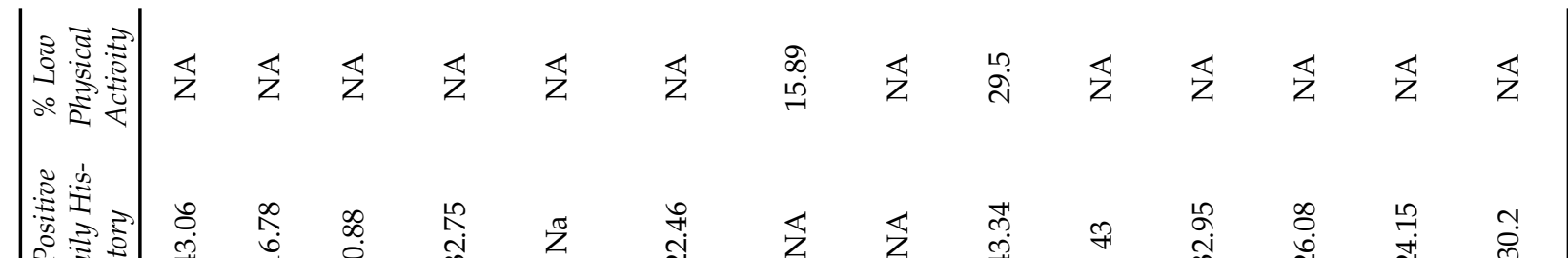

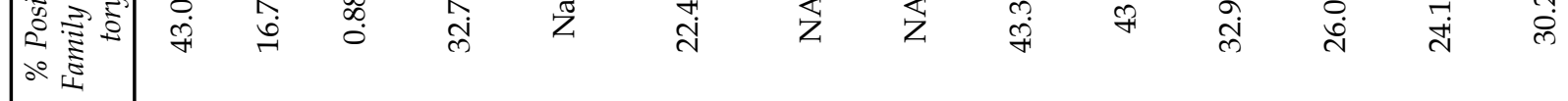

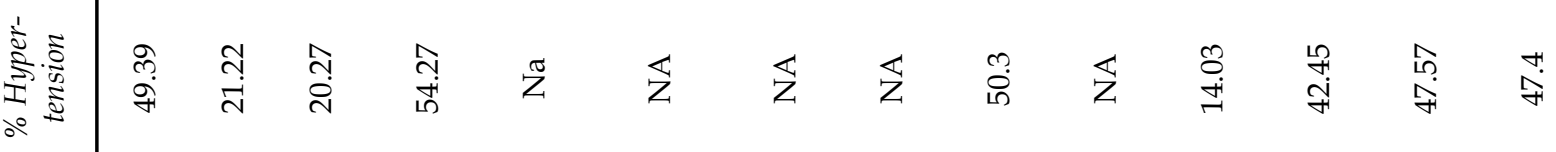

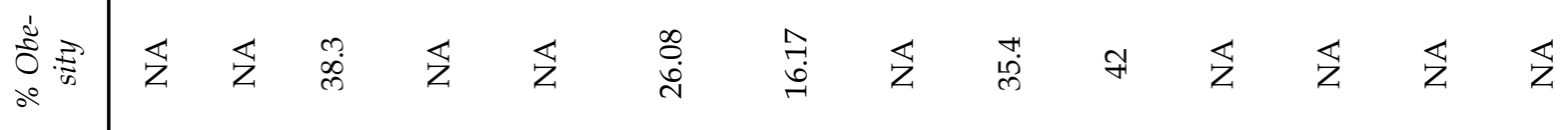

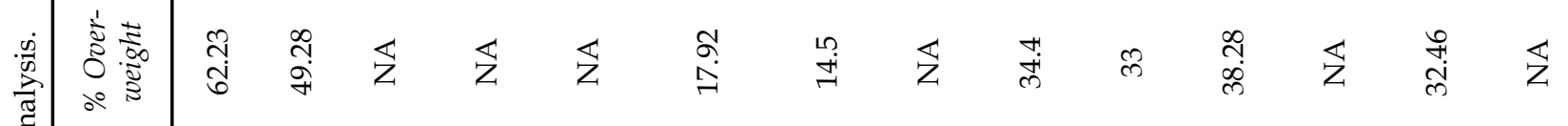

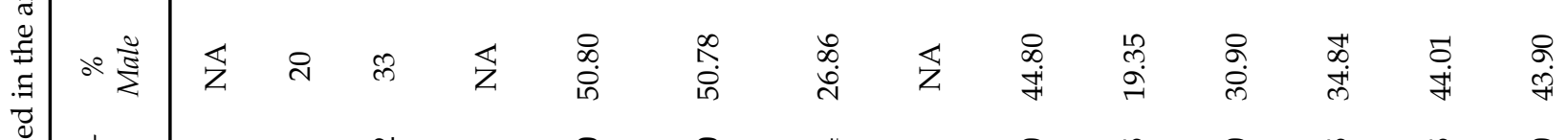

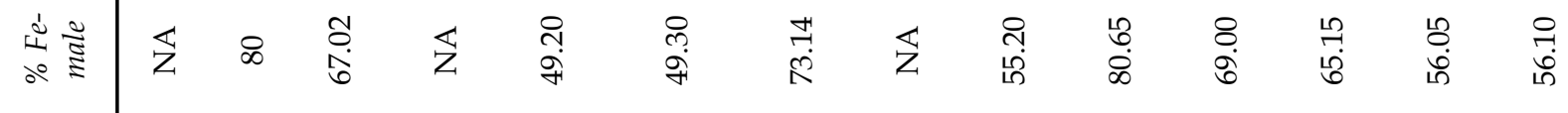

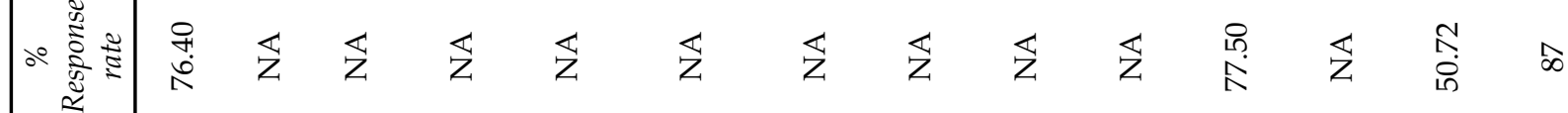

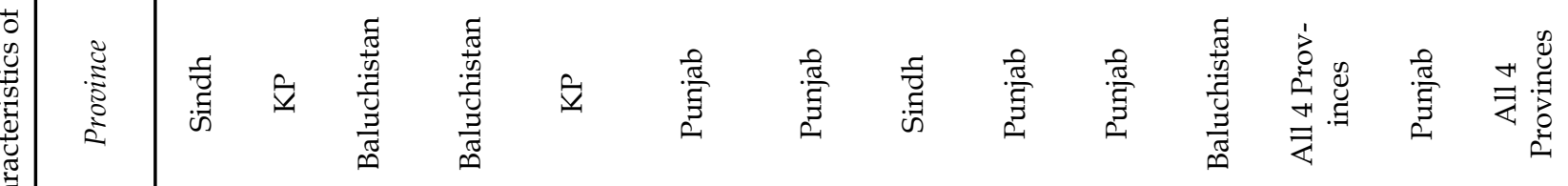

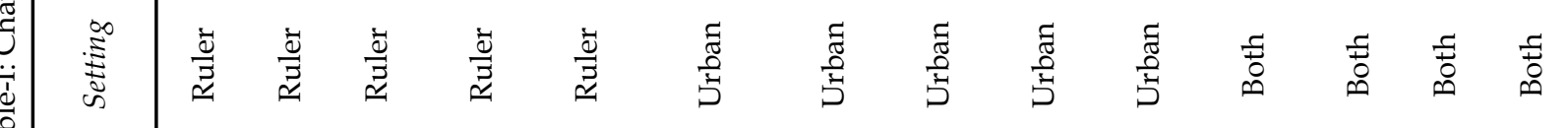

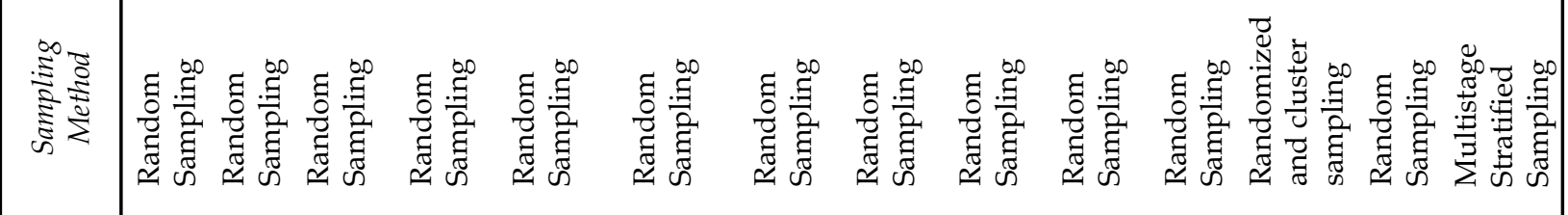

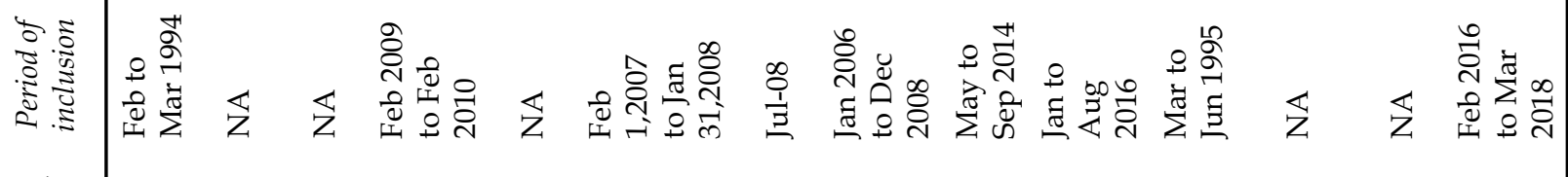
竎菅离

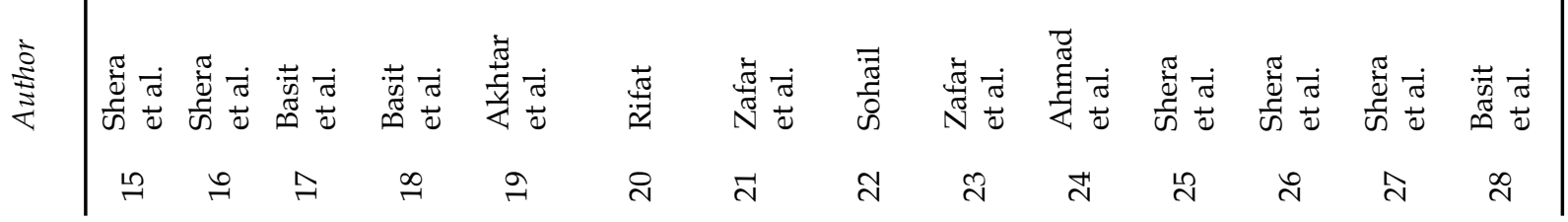


reviewing titles and abstracts, 56 articles were found irrelevant and then excluded from the process. As a result, only 65 studies were selected for full-text reading. Later, 56 articles were excluded after full text read for the following reasons: articles with no numerical prevalence measure(s) of diabetes; studies that were not based in Pakistan; studies with no clear assessment methods or grading systems of diabetes; studies based on hospital data set or eligibility criteria not met or full-text did not include relevant indicators. Finally, only 14 articles met the inclusion criteria and data were extracted for the analysis. The flow chart of study selection process is presented in Fig.1, considered from the PRISMA flow diagram. ${ }^{6}$

Methodological quality and characteristics of included studies: All studies were cross-sectional. The simple random sampling procedure was used 12 out of 14 studies. The articles were published between 1995 and 2018 while the period of subject inclusion was from Feb. 1995 to Mar. 2017. Diabetes was reported based on the self-reporting (known diabetes) and different diagnostic tests: A1C criteria, fasting plasma glucose (FPG) and 2-h plasma glucose (2-h PG). All the four provinces of Pakistan were represented in articles. Five studies were conducted in a rural regions ${ }^{15-19}$ while five in an urban region ${ }^{20-24}$ and four in both regions. ${ }^{25-28}$ The proportion of females ranged from $49.20 \%$ to $81.65 \%$. The mean age varied from 18 to 76 years (14 studies). ${ }^{15-28}$ The proportion of hypertension ranged from $14.4 \%$ to $43.43 \% .{ }^{16-18,23,25-28}$ The proportion of people who had positive family history varied from $0.88 \%$ to $43.3 \%$ (11 studies). ${ }^{15-18} 2023-28$ Obesity ranged from $16.16 \%$ to $42 \%$ (5 studies). $16,17,19,20,22$, The proportion of people with overweight body mass index ranged from $17.93 \%$ to $62.23 \%$ (8 studies). ${ }^{15,16,20-24,27}$ The statistics of the included studies were presented in Table-I.

\section{RESULTS}

Statistical analyses of prevalence of diabetes and prediabetes are presented in Table-II. The pool prevalence of diabetes was $14.62 \%$ (95\% CI: 10.651$19.09, \mathrm{I}^{2}=99.3 \%, 14$ studies) in a total sample of 49,418

Table-II: Prevalence of diabetes, prediabetes and its risk factors in the adult population of Pakistan, from Jan. 1995 to Aug. 2018.

\begin{tabular}{lccccccc}
\hline Column1 & Studies & Sample & Cases & Prevalence, $\%(95 \% \mathrm{CI})$ & $I^{2}, \%$ & Heterogeneity & P-Egger test \\
\hline Diabetes & 14 & 49418 & 6884 & $14.62(10.651-19.09)$ & 0.993 & $<0.001$ & 0.6559 \\
Undiagnosed & 6 & 36748 & 1443 & $9.27(3.25-17.94)$ & 0.997 & $<0.001$ & 0.1267 \\
Prediabetes & 10 & 26999 & 3185 & $11.43(8.26-15.03)$ & 0.985 & $<0.001$ & 0.6508 \\
By Sex & & & & & & & 0.0278 \\
Male & 10 & 6131 & 817 & $14.80(9.83-20.59)$ & 0.982 & $<0.0001$ & \\
Female & 10 & 11011 & 1811 & $15.83(10.05-22.63)$ & 0.976 & $<0.0001$ & \\
By setting & & & & & & & 0.374 \\
Urban & 5 & 5472 & 845 & $17.72(12.22-23.98)$ & 0.969 & $<0.001$ & \\
Ruler & 7 & 10969 & 1206 & $12.10(8.75-15.89)$ & 0.969 & $<0.001$ & \\
By Age & 5 & & & & & & \\
25-34 & 5 & 3119 & 93 & $3.24(2.32-4.30)$ & 0.5 & 0.0915 & 0.0044 \\
35-44 & 5 & 2544 & 275 & $12.83(8.43-17.97)$ & 0.909 & $<0.001$ & \\
45-54 & 5 & 2212 & 365 & $19.52(13.56-26.25)$ & 0.918 & $<0.001$ & \\
55-64 & 5 & 1642 & 288 & $20.73(14.69-27.50)$ & 0.886 & $<0.001$ & \\
65-74 & 5 & 855 & 160 & $21.84(15.36-30.08)$ & 0.817 & 0.0002 & \\
75+ & 5 & 319 & 60 & $18.86(8.16-37.81)$ & 0.871 & $<0.001$ & \\
By Province & & & & & & & \\
Panjab & 6 & 11809 & 2685 & $18.52(10.74-27.82)$ & 0.992 & $<0.001$ & $<0.001$ \\
Sindh & 3 & 22709 & 2683 & $19.25(5.60-38.48)$ & 0.998 & $<0.001$ & \\
Baluchistan & 4 & 5238 & 675 & $15.25(8.56-23.43)$ & 0.982 & $<01$ & \\
Khyber & 3 & 4229 & 575 & $13.98(10.39-18.00)$ & 0.923 & $<0.001$ \\
Pakhtunkhwa & 5 & & & & &
\end{tabular}


participants (Fig.2). The funnel plot (Fig.3) showed publication bias which is confirmed by the Egger's test $(p=0.656)$. The prevalence of prediabetes was $11.43 \%$ (95\%CI: 8.26-15.03, $\mathrm{I}^{2}=98.50 \%, 10$ studies) in a total sample size of 26,999 individuals. The forest plot of prediabetes in presented in Fig.4. The prevalence of undiagnosed diabetes was $9.27 \%$ (95\% CI: $3.25-17.94), \mathrm{I}^{2}=99.70 \%, 6$ studies) in a total sample size of 36,748 individuals.

Source of heterogeneity and subgroup analysis: In Table-II, subgroup analysis stratified by genderprevalence among females were revealed to be $15.83 \%$ higher than males $14.80 \%(10.05 \%-22.63 \%)$ females, while in male $14.80 \%(9.83 \%-20.59 \%)$. Pooled prevalence of agegroups in 25-34 yrs, 35-44 yrs, 45-54 yrs and 55-64 yrs, 65-74 yrs and 75+ yrs were $3.24 \%(2.32 \%-4.30 \%), 12.83 \%(8.43 \%-17.97 \%)$, $19.52 \%(13.56 \%-26.25 \%), 20.73 \%(14.69 \%-27.50 \%)$, $21.84 \%$ (15.36\%-30.08\%), and $21.84 \%$ (15.36\%$30.08 \%)$, respectively. The prevalence in the 6574 years age-group was the highest of the six age groups, and the prevalence of diabetes increased with age gradually. With regard to province studies, the prevalence of diabetes was high $19.25 \%$ (5.60\%-38.48\%) of Sindh, compared with $18.52 \%$ $(10.74 \%-27.82 \%)$ of Punjab, $15.25 \%(8.56 \%-23.43 \%)$ of Baluchistan and $13.98 \%(10.39 \%-18.00 \%)$ of Khyber Pakhtunkhwa.

The subgroup analysis of diabetes is presented in Table-II. The prevalence of diabetes increases with the growing age. The prevalence of diabetes between male and female was insignificant and between urban and rural regions. There was no significant publication bias for all subgroup analyses. Using the univariate meta regression analysis, the prevalence of diabetes increased sharply with age $(\beta=0.49 \%$, $95 \%$ CI: $0.21-0.78, \mathrm{p}<0.001$ with $\left.R^{2}=75.63\right)$, the proportion of participants with hypertension $(\beta=$ $0.40 \%, 95 \%$ CI: $\left.0.06-0.75, \mathrm{p}=0.022, R^{2}=40.80\right)$, the

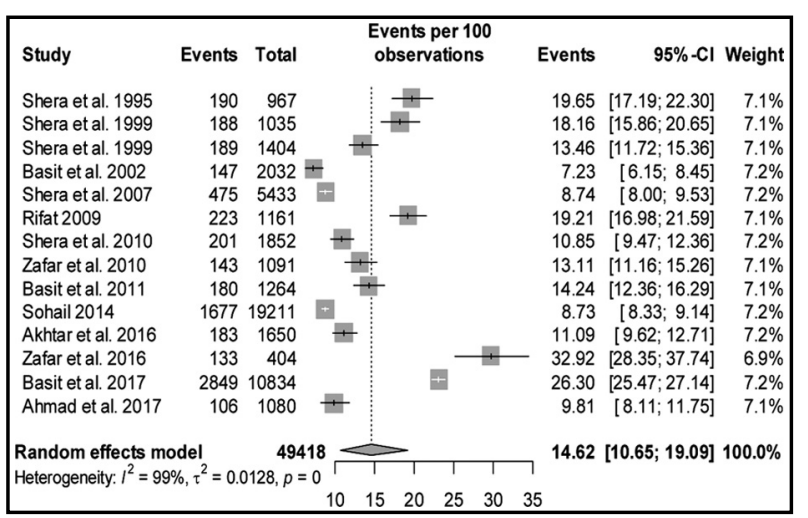

Fig.2: Forest plot of prevalence of diabetes from population Jan. 1995 to Aug. 2018.

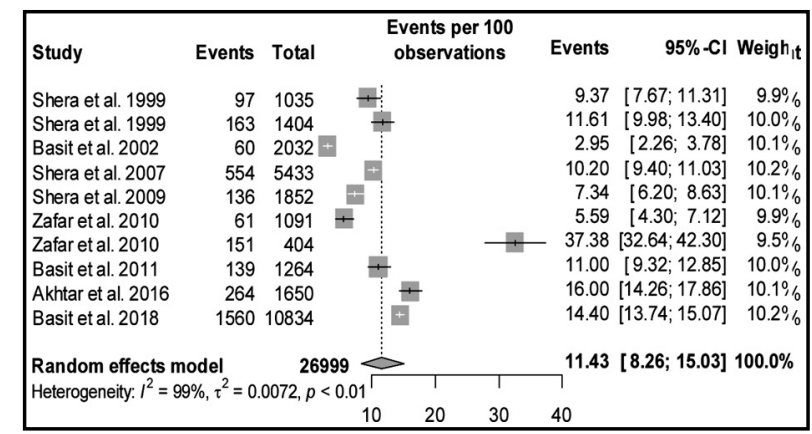

Fig.3: Forest plot of prevalence of prediabetes from population Jan. 1995 to Aug. 2018.

proportion of participants with a family history of diabetes $(\beta=0.45 \%, 95 \%$ CI: $0.08-0.82, p=0.018$, $\left.R^{2}=30.35\right)$ and BMI $(\beta=0.21 \%, 95 \%$ CI: 0.02-0.4, $\mathrm{p}$ $=0.0295, R^{2}=21.32$ ). The prevalence of diabetes was not correlated with smoking at the time of data collection, inclusion time period, physical inactivity and waist hip ratio obesity.

\section{DISCUSSION}

To the best of our knowledge, this is the first study to determine the prevalence of and risk factors for diabetes in Pakistan using a systematic review and meta-analysis. The pooled prevalence of diabetes was revealed $14.62 \%$ (based on 49,418 individuals) which suggest that there has been a significant increase in the prevalence of diabetes in Pakistan. Furthermore, the selected studies in this meta-analysis cover almost all geopolitical zones of Pakistan, making it possible to determine regional differences in the prevalence of Diabetes. Diabetes is affecting all around the country, with the highest prevalence seen in the Sindh province and with the lowest in Khyber Pakhtunkhwa. Growing age, family history, hypertension, overweight, are important risk factors for diabetes among Pakistanis. A nationwide diabetes care survey and prevention policy is highly recommended.

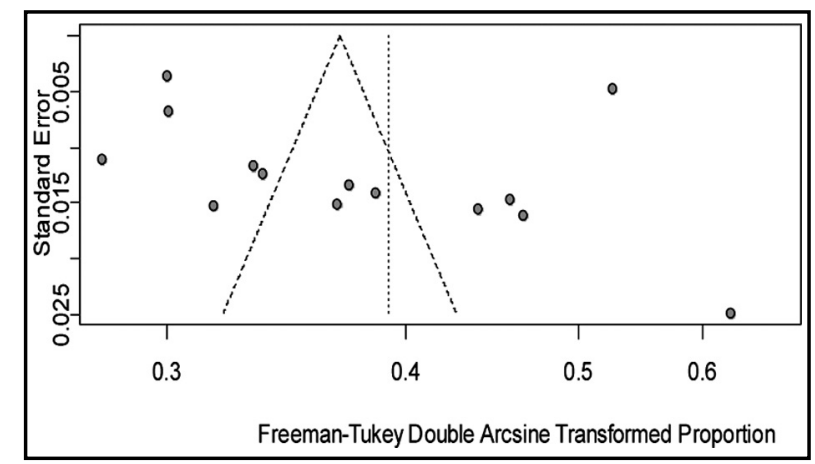

Fig.4: Funnel plot of the prevalence of diabetes in Pakistan from Jan. 1995 to Aug. 2018. 
Limitations of the study: Out of fourteen selected studies, only two surveys reported countrywide prevalence. Secondly, the fact that we selected studies which used different screening methods for the diagnosis of diabetes means that some people with the disease could have been missed. Furthermore, significant heterogeneity was found in combining the prevalence rates of diabetes. The main sources of heterogeneity in the included studies related to the different characteristics of study population.

\section{Grant Support E Financial Disclosures: None.}

\section{REFERENCES}

1. Al-Rubeaan K, Youssef AM, Subhani SN, Ahmad NA, AlSharqawi AH, Al-Mutlaq HM, et al. Diabetic nephropathy and its risk factors in a society with a type 2 diabetes epidemic: A Saudi Nat Diabet Registry-based Study. PLoS ONE. 2014;9(2):e88956. doi:10.1371/journal.pone.0088956

2. Ogurtsova K, da Rocha Fernandes JD, Huang $Y$ Linnenkamp U, Guariguata L, Cho NH, et al. IDF Diabetes Atlas: Global estimates for the prevalence of diabetes for 2015 and 2040. Diabetes Res Clin Pract. 2017;128:40-50. doi: 10.1016/j.diabres.2017.03.024.

3. Cho NH, Shaw JE, Karuranga S, Huang Y, da Rocha Fernandes JD, Ohlrogge AW, et al. IDF Diabetes Atlas: Global estimates of diabetes prevalence for 2017 and projections for 2045. Diabetes Res Clin Pract. 2018;138:271281. doi: 10.1016/j.diabres.2018.02.023.

4. Huizen J. Type 2 diabetes and life expectancy, Medical News Today, 2017. May 16, Retrieved from: https://www. medicalnewstoday.com/articles/317477.php.

5. Hu FB. Globalization of diabetes: the role of diet lifestyle, and genes. Diabetes Care. 2011;34(6):1249-1257. doi: $10.2337 /$ dc11-0442.

6. Moher D, Liberati A, Tetzlaff J, Altman DG, The PRISMA Group. Preferred reporting items for systematic reviews and meta-analyses: the PRISMA statement. PLoS Med. 2009;6(7):e1000097. doi:10.1371/journal.pmed.1000097.

7. Barendregt JJ, Doi SA, Lee YY, Norman RE, Vos T. Metaanalysis of prevalence. J Epidemiol Community Health. Medline. 2013;67:974-978. doi:10.1136/jech-2013-203104

8. Higgins JP, Green S. Cochrane handbook for systematic reviews of interventions. Vol 5. Oxford: Wiley Online Library; 2008.

9. R Development Core Team R: A language and environment for statistical computing. $\mathrm{R}$ Foundation for Statistical Computing, Vienna Austria. 2008. ISBN 3-900051-07-0.

10. Barendregt JJ, Doi SA, Lee YY, Norman RE, Vos T. Metaanalysis of prevalence. J Epidemiol Community Health 2013;67(11):974-978. doi: 10.1136/jech-2013-203104

11. Cochran GW. The Combination of Estimates from Different Experiments. Biometrics. 1954;10:101-129.

12. Higgins JPT, Thompson SG. Quantifying heterogeneity in a meta-analysis. Stat Med. 2002;21:1539-1558. doi: 10.1002/ sim.1186.

13. Egger M, Davey Smith G, Schneider M, Minder C. Bias in meta-analysis detected by a simple, graphical test. BMJ. 1997;315:629-634. doi: 10.1136/bmj. 315.7109.629.

14. Duval S, Tweedie R. Trim and fill: A simple funnel-plotbased method of testing and adjusting for publication bias in meta-analysis. Biometrics. 2004;56(2):455-463. doi: 10.1111/j.0006-341X.2000.00455.x
15. Shera AS, Rafique G, Khwaja IA, Ara J, Baqai S, King H. Pakistan national diabetes survey: prevalence of glucose intolerance and associated factors in Shikarpur, Sindh Province. Diabetic Med. 1995;12(12):1116-1121. doi:10.1111/j.1464-5491.1995.tb00430.x.

16. Shera AS, Rafique G, Khwaja IA, Ara J, Baqai, S, King H. Pakistan National Diabetes Survey prevalence of glucose intolerance \& associated factors in North West at Frontier Province (NWFP) of Pakistan. Pak J Med Sci. 1999;49:206-211.

17. Basit A, Hydrie MZ, Ahmed K, Hakeem R. Prevalence of diabetes, impaired fasting glucose and associated risk factors in a rural area of Baluchistan province according to new ADA criteria. Pak J Med Sci. 2002;52(8):357-360.

18. Basit A, Alvi SFD, Fawwad A, Ahmad K, Ahmedani MY. Temporal changes in the prevalence of diabetes, impaired fasting glucose and its associated risk factors in the rural area of Baluchistan. Diabetes Res Clin Pract. 2011;94:456462. doi: 10.1016/j.diabres.2011.08.009.

19. Akhtar S, Khan Z, Rafiq M, Khan A. Prevalence of Type II diabetes in District Dir Lower in Pakistan Pak J Med Sci. 2016;32(3):622-625. doi: 10.12669/pjms.323.9795.

20. Rifat-uz-Zaman. High Prevalence of Diabetes mellitus and Promoting Factors among Human Urban Population of Bahawalpur-district, Pakistan: Cross-sectional Study. Res J Med Sci. 2009;3(2):62-69.

21. Zafar J, Bhatti F, Akhtar N, Rasheed U, Humayun S, Waheed A, et al. Prevalence and risk factors for diabetes mellitus in a selected urban population of a city in Punjab. J Pak Med Assoc. 2011;61(1):40-47.

22. Sohail M. Prevalence of Diabetic Retinopathy among Type-2 Diabetes Patients in Pakistan-Vision Registry. Pak J Ophthalmol. 2014;30(4):204-212.

23. Zafar J, Nadeem D, Khan SA, Jawad Abbasi MM, Aziz F, Saeed S. Prevalence of diabetes and its correlates in urban population of Pakistan: A Cross-sectional survey. J Pak Med Assoc. 2016;66(8):922-927.

24. Ahmed H, Thaver I, Manzoor I. "Risk factors associated with diabetes in periurban community, Lahore Pakistan, Pak J Med Sci. 2017;33(6):1381-1384. doi: 10.12669/ pjms.336.13323.

25. Shera AS, Rafique G, Khwaja IA, Ara J, Baqai S, King H. Pakistan National Diabetes Survey: prevalence of glucose intolerance and associated factors in Baluchistan province. Diabetes Res Clin Pract. 1999;44(1):49-58.

26. Shera AS, Jawad F, Maqsood A. Prevalence of diabetes in Pakistan. Diabetes Res Clin Pract. 2007;76(2):219-222. doi: 10.1016/j.diabres.2006.08.011.

27. Shera AS, Basit A, Fawwad A, Hakeem R, Ahmedani MY, Hydrie MZ, et al. Pakistan National Diabetes Survey: prevalence of glucose intolerance and associated factors in the Punjab Province of Pakistan. Prim Care Diabetes. 2010;4:79-83.

28. Basit A, Fawwad A, Qureshi H, Shera AS. Prevalence of diabetes, pre-diabetes and associated risk factors: second National Diabetes Survey of Pakistan (NDSP), 2016-2017. BMJ Open. 2018;8(8). doi: 10.1136/bmjopen-2017-020961.

\section{Authors' Contribution:}

SA, JAN \& TA: Conceived, designed and did statistical analysis \& editing of manuscript.

SA, AS \& TA: Did data collection and manuscript writing.

SA, JAN \& AS: Did review and final approval of manuscript. 